Short communication

\title{
Electron microscopy analysis of carboxymethylcellulase in rhizobia
}

\author{
Chun-Yi Hu ${ }^{\mathrm{a}, *}$, Wen-Sheng Tseng ${ }^{\mathrm{b}, 1}$, Shu-Ling Hsieh ${ }^{\mathrm{a}, 1}$, Yo-Chia Chen ${ }^{\mathrm{c}}$, Hsueh-Ling Cheng ${ }^{\mathrm{c}}$, \\ Shang-Shyng Yang ${ }^{\mathrm{d}}$ \\ ${ }^{a}$ Department of Nutrition and Health Science, Fooyin University, Ta-Liao Hsiang, Kaohsiung 831, Taiwan \\ ${ }^{\mathrm{b}}$ Department of Horticulture, National Taiwan University, Taipei 106, Taiwan \\ ${ }^{\mathrm{c}}$ Graduate Institute of Biotechnology, National Pingtung University of Science and Technology, Pingtung 912, Taiwan \\ ${ }^{\mathrm{d}}$ Institute of Microbiology and Biochemistry, National Taiwan University, Taipei 106, Taiwan
}

\section{A R T I C L E I N F O}

Article history:

Received 24 July 2008

Received in revised form

25 November 2008

Accepted 1 December 2008

Available online 25 December 2008

Keywords:

Rhizobia

Carboxymethylcellulase

Immunogold

Induction

Flavonoid

\begin{abstract}
A B S T R A C T
Here we analyzed carboxymethylcellulase (CMCase; EC 3, 2, 1, 4), one of the key enzymes in the early symbiotic process, in Rhizobium. Specific immunogold labeling of electron microscopy was confirmed in Sinorhizobium fredii BCRC15769, ATCC35423, Sinorhizobium meliloti ATCC9930, and barely detected in Bradyrhizobium japonicum BCRC13528, ATCC10324 and Rhizobium rhizogenes ATCC11325. Non-specific labeling was detected in Rhizobium leguminosarum bv. viceae ATCC10004, Rhizobium leguminosarum bv. trifolii ATCC10328, and Mesorhizobium loti ATCC33669. Treatment of S. fredii BCRC15769 in the early log phase with the flavonoid genistein caused relocalization of CMCase. Together our data suggests a role for CMCase in early symbiosis.
\end{abstract}

(ㄷ) 2008 Elsevier Ltd. All rights reserved.
The infection of legume roots by rhizobia is a complex process with a high degree of specificity. Carboxymethylcellulase (endo$1,4-\beta$-D-glucanase, or CMCase) is likely involved in the initial infection stage (Bhat and Bhat, 1997), and several hypotheses have been proposed to explain how these events occur. One of the models proposes that wall-degrading enzymes cause localized degradation that completely traverses the root-hair wall, allowing direct penetration by the bacteria (Dazzo and Hubbell, 1982).

During the 1990s, several researchers attempted to develop a new approach for enzyme identification (Mateos et al., 1992; Jimenez-zurdo et al., 1996a,b; Iannetta et al., 1997) using an activity gel overlay detection method. Two CMCase isozymes were determined from a native stain assay, and gel filtration revealed the molecular weights to be approximately 196 and $30 \mathrm{kDa}$ (Hu and Lin, 2003). Michaud et al. (2002) isolated the coding sequence for EndS from Sinorhizobium meliloti M5N1CS DNA and compared the deduced amino acid sequence of the mature EndS (337 amino acids, molecular mass $36,418 \mathrm{Da}$, isoelectric point 4.92 ) to those of published $\beta$-glycanases, and confirmed that EndS belongs to family 5 of the glycoside hydrolases. Furthermore, EndS is similar to the

\footnotetext{
* Corresponding author. Tel.: +886 7 7862240; fax: +886 77826740

E-mail address: mt121@mail.fy.edu.tw (C.-Y. Hu).

1 These authors made equal contributions.
}

37-kDa subunit of isozyme 1 in Sinorhizobium fredii BCRC15769 (Hu and Lin, 2003). A $1047 \mathrm{bp}$ open reading frame that functions in the hydrolyzation of carboxymethyl cellulose was identified from the cel8A gene in Rhizobium leguminosarum bv. trifolii 1536, and the 3.1kb genomic DNA fragment from $R$. leguminosarum bv. trifolii 1536 was obtained. The cel8A gene encodes a glycosyl hydrolase family 8 member of 348 amino acids that exhibits a molecular mass of $35 \mathrm{kDa}$ when induced from Escherichia coli DH5 $\alpha$ (An et al., 2004).

In our previous study, we used ion-exchange chromatography and electroelution to purify CMCase, and characterized its activity using activity staining (Hu and Lin, 2003). Furthermore, we generated antibodies against CMCase and assessed the specificity of the antiserum by Western analysis, and cell distribution of CMCase was examined using immuno-microscopy. CMCase was demonstrated to be a cellulytic enzyme, consistent with the results of other biochemical studies (Mateos et al., 1992; Jimenez-zurdo et al., 1996b; Hu and Lin, 2003). To extend the findings from immunogold labeling of CMCase distribution, the aim of the research was to treat different species of rhizobia and reveal the different flavonoid compounds present in rhizobia.

The rhizobial strains used in the study were S. fredii BCRC15769 (host legume: Glycine max L. Merril) isolated from indigenous soil in Taiwan, S. fredii ATCC35423, Bradyrhizobium japonicum BCRC13528, ATCC10324, Rhizobium rhizogenes ATCC11325, Rhizobium leguminosarum bv. viceae ATCC10004, Rhizobium leguminosarum bv. trifolii 
ATCC10328, and Mesorhizobium loti ATCC33669, S. meliloti ATCC9930, which were purchased from Bioresource Collection and Research Center (BCRC), Food Industry Research and Development Institute, Hsinchu City, Taiwan. Bacterial strains were stored in yeast-mannitol agar at $4{ }^{\circ} \mathrm{C}$ (Mergaert et al., 1995). Bacteria were maintained on BIII agar (Morales et al., 1984), and cultured aerobically in BIII broth at $28^{\circ} \mathrm{C}$ with agitation. Cells were cultivated until late log phase $\left(9 \times 10^{8}\right.$ cells $/ \mathrm{ml}$, measured using a Petroff Hausser counting chamber) and $0.5 \mathrm{~g}$ (wet weight) was resuspended in $1.0 \mathrm{M}$ potassium phosphate buffer ( $\mathrm{pH} 7.0)$ and incubated for $30 \mathrm{~min}$ at room temperature with continuous stirring. Procedures for pretreatment, immunogold labeling of cells, and examination by transmission electron microscope were followed from $\mathrm{Hu}$ et al. (2006). Statistical significance $(p<0.05)$ for the differences between means was determined by one-way ANOVA and Tukey Post Hoc test, and calculations were performed using SPSS 10.07 (SPSS for Windows, Inc., Chicago, IL, USA).

BIII broth was supplemented with the 5 flavonoids (final concentration of $0.2 \mu \mathrm{M})$ : apigen, chrysin, daidzein, genistein, naringenin, which were purchased from Sigma (St. Louis, MO.). Rhizobial cells were cultivated until late log phase and centrifuged at $8000 \times \mathrm{g}$ for $30 \mathrm{~min}$ at $4{ }^{\circ} \mathrm{C}$. Cultivation and induction methods were followed by Lin et al. (1999). The resting protocols for EM pretreatment and immunolabelling of cells were described by $\mathrm{Hu}$ et al. (2006).

Immunogold labeling for electron microscopic observations was performed with ultrathin sections of S. fredii BCRC15769 (Fig. 1a). Specific immunogold labeling was barely detected in B. japonicum
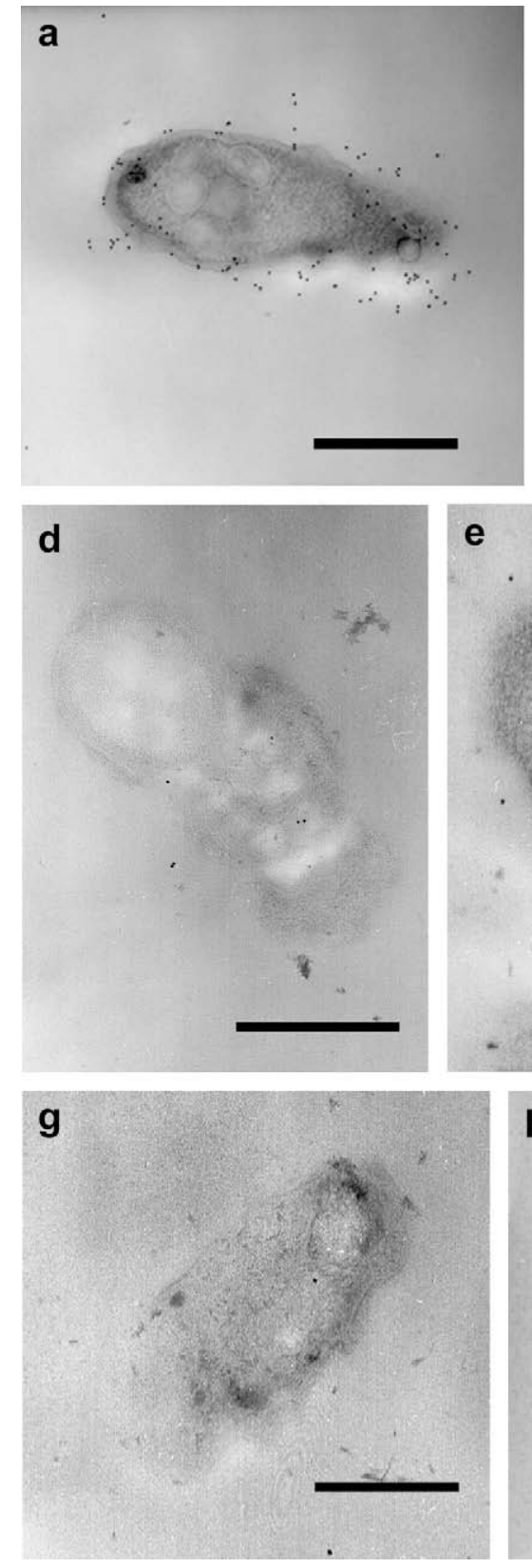

\section{b}
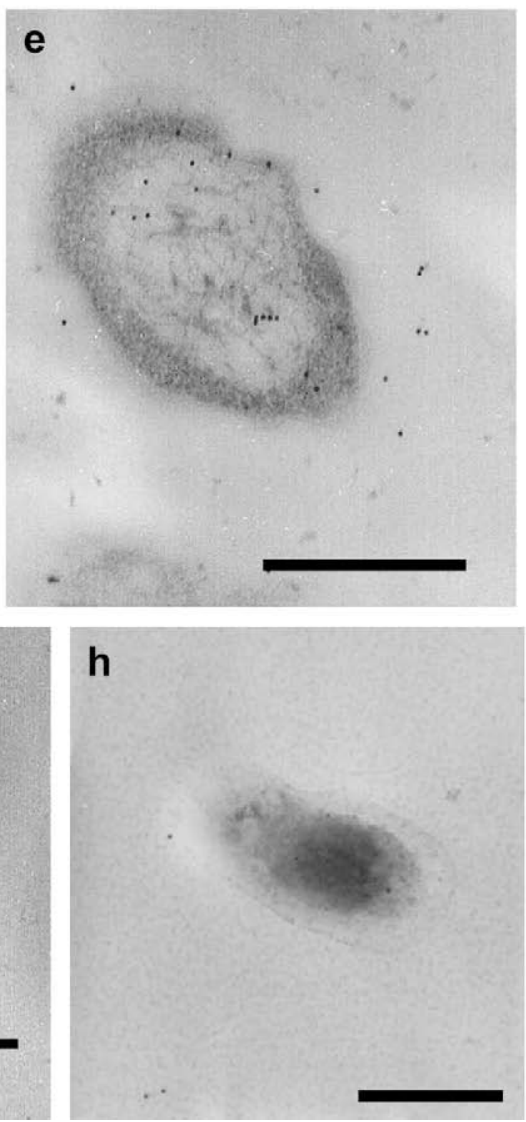
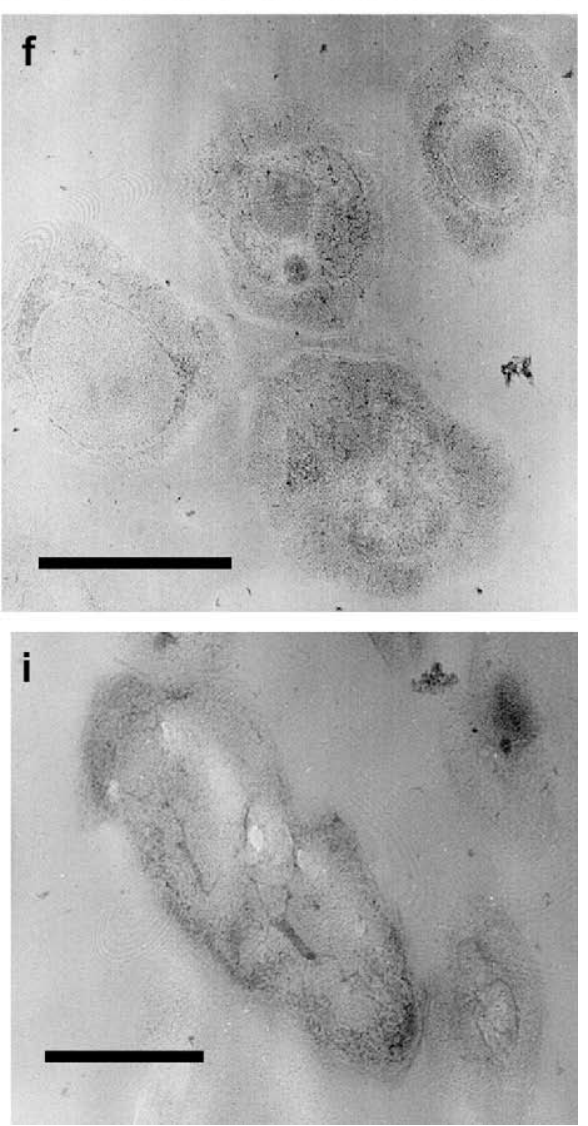

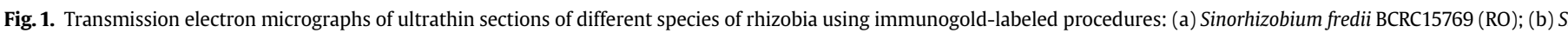

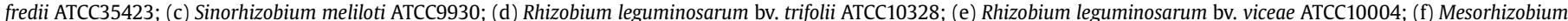

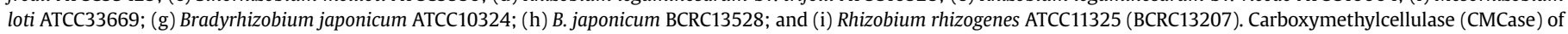
the intact gold-labeled $(10 \mathrm{~nm})$ bacterial cell. Bar $=500 \mathrm{~nm}$. 
Table 1

Results of quantitative evaluations of the distribution of colloidal gold particles as revealed by analysis of ultrathin sections of different species and treatment of rhizobia.

\begin{tabular}{|c|c|c|c|c|c|c|}
\hline \multirow[t]{2}{*}{ Organism $^{c}$} & \multirow{2}{*}{$\begin{array}{l}\text { Pretreatment } \\
\text { with } 1 \% \mathrm{OsO}_{4}\end{array}$} & \multicolumn{4}{|c|}{ Mean (\%) of colloidal gold \pm SD } & \multirow[t]{2}{*}{ Percentage $^{\mathrm{e}}(\%)$} \\
\hline & & Total amount & Membrane associated & Periplasmic space $^{\mathrm{d}}$ & Cytoplasmic space & \\
\hline \multirow[t]{2}{*}{ Sinorhizobium fredii BCRC15769 } & No & $97.3 \pm 3.1$ & $17.3 \pm 1.5^{\mathrm{a}}$ & $54.0 \pm 3.0^{\mathrm{a}}$ & $26.7 \pm 2.1^{\mathrm{a}}$ & 73.3 \\
\hline & Yes & $56.0 \pm 1.7$ & $21 \pm 1.5^{\mathrm{a}}$ & $27.7 \pm 1.5^{\mathrm{a}}$ & $7.7 \pm 1.5^{\mathrm{a}}$ & 87 \\
\hline S. fredii АТСС 35423 & No & $51.3 \pm 2.1$ & $19.3 \pm 1.5^{\mathrm{a}}$ & $24.7 \pm 1.5^{\mathrm{a}}$ & $6.3 \pm 0.6^{\mathrm{a}}$ & 85.8 \\
\hline Sinorhizobium meliloti ATCC9930 & No & $4.0 \pm 0.0$ & $0.0 \pm 0.0^{\mathrm{a}, \mathrm{b}}$ & $2.0 \pm 0.0^{\mathrm{a}}$ & $2.0 \pm 0.0^{\mathrm{b}}$ & 50 \\
\hline Rhizobium leguminosarum bv. trifolii ATCC10328 & No & $5.0 \pm 0.0$ & $1.0 \pm 0.0^{\mathrm{a}}$ & $1.0 \pm 0.0^{b}$ & $3.0 \pm 0.0^{\mathrm{a}, \mathrm{b}}$ & 40 \\
\hline Rhizobium leguminosarum bv. viceae ATCC10004 & No & $18.7 \pm 1.5$ & $2.0 \pm 0.0^{\mathrm{a}}$ & $5.0 \pm 0.0^{\mathrm{a}}$ & $10.6 \pm 1.5^{\mathrm{a}}$ & 37.4 \\
\hline Mesorhizobium loti ATCC33669 & No & $12.0 \pm 2.0$ & $2.0 \pm 0.0^{\mathrm{a}}$ & $3.0 \pm 0.0^{\mathrm{a}}$ & $6.7 \pm 0.6^{\mathrm{a}}$ & 41.7 \\
\hline Bradyrhizobium japonicum ATCC10324 & No & $4.0 \pm 0.0$ & $0.0 \pm 0.0^{\mathrm{a}}$ & $1.0 \pm 0.0^{\mathrm{a}}$ & $3.0 \pm 0.0^{\mathrm{a}}$ & 25 \\
\hline B. japonicum BCRC13528 & No & $8.7 \pm 0.6$ & $1.0 \pm 0.0^{\mathrm{a}}$ & $0.0 \pm 0.0^{\mathrm{b}}$ & $7.7 \pm 1.5^{\mathrm{a}, \mathrm{b}}$ & 11.5 \\
\hline Rhizobium rhizogenes ATCC11325 & No & $16.3 \pm 1.5$ & $1.0 \pm 0.0^{\mathrm{a}}$ & $0.7 \pm 0.6^{\mathrm{b}}$ & $14.7 \pm 0.6^{\mathrm{a}, \mathrm{b}}$ & 10.4 \\
\hline
\end{tabular}

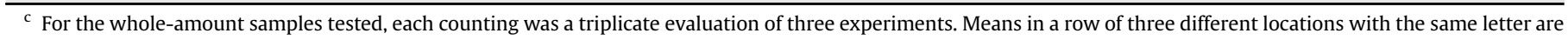
significantly different, $p<0.05$.

d Periplasmic, associated with cytoplasmic and outer membranes.

e Percentage of colloidal gold particles (\%): (membrane associated + periplasmic space) $\times 100 /$ total amount.

ATCC10324 (Fig. 1g), BCRC13528 (Fig. 1h), and R. rhizogenes ATCC11325 (Fig. 1i). Non-specific labeling was detected in $R$. leguminosarum bv. trifolii ATCC10328 (Fig. 1d), R. leguminosarum bv. viceae ATCC10004 (Fig. 1e), and Rhizobium loti ATCC33669 (Fig. 1f), demonstrating highly contrasting intra- and interspecific CMCase similarities. However, specific labeling was observed in S. fredii BCRC15769 (RO) (Fig. 1a), ATCC35423 (Fig. 1b), and S. meliloti ATCC9930 (Fig. 1c).

Table 1 presents the results of quantitative evaluations of label distribution. The quantification of colloidal gold in a cell was assessed in three regions: the membrane-associated region, the periplasmic space, and the cytoplasmic space. We determined the percentage of colloidal gold particles using the following calculation:

\section{(amount membrane-associated}

+ amount in the periplasmic space) $\times 100 /$ total amount,

Species and treatments could be divided into three groups based on the percentage of particles aggregating in the cell membrane: one group with $100-50 \%$ in the membrane, the second from $50 \%$ to $30 \%$, and the third group below $30 \%$.
Within the group with the highest percentage of particles in the cell membrane (group 1), the highest percentage of $87.0 \%$ was $S$. fredii $\mathrm{BCRC} 15769$ with $\mathrm{OsO}_{4}$ treatment, followed by $S$. fredii ATCC35423 (85.8\%), S. fredii BCRC15769 without $\mathrm{OsO}_{4}$ treatment (73.3\%), and S. meliloti ATCC9930 (50.0\%).

The second group included M. loti ATCC33669 (41.7\%); R. leguminosarum bv. trifolii ATCC10328 (40.0\%), and R. leguminosarum bv. viceae ATCC10004 (37.4\%). Finally, the third group included 2 genera of rhizobia: Bradyrhizobium spp. and R. rhizogenes, which are slowgrowing rhizobia or have different hosts: B. japonicum ATCC10324 (25.0\%), B. japonicum BCRC13528 (11.5\%), and Rhizobium rhizogenes ATCC11325 (10.4\%).

The effects of the flavonoids genistein on CMCase distribution are shown in Fig. 2a,b. Addition of $20 \mu \mathrm{M}$ genistein in the cultivation stage caused CMCase to aggregate towards two sides of the cell. In contrast, apigenin, chrysin, daidzein, and narigenin had little effect on the distribution of CMCase.

Vessey and Chemining'wa (2006) reported the genetic diversity of $R$. leguminosarum bv. viciae in cultivated soils of an eastern Canadian prairie by comparing PCR-RFLP patterns. Aguilar et al. (2006) analyzed symbiotic genes showing 16SrRNA RFLP
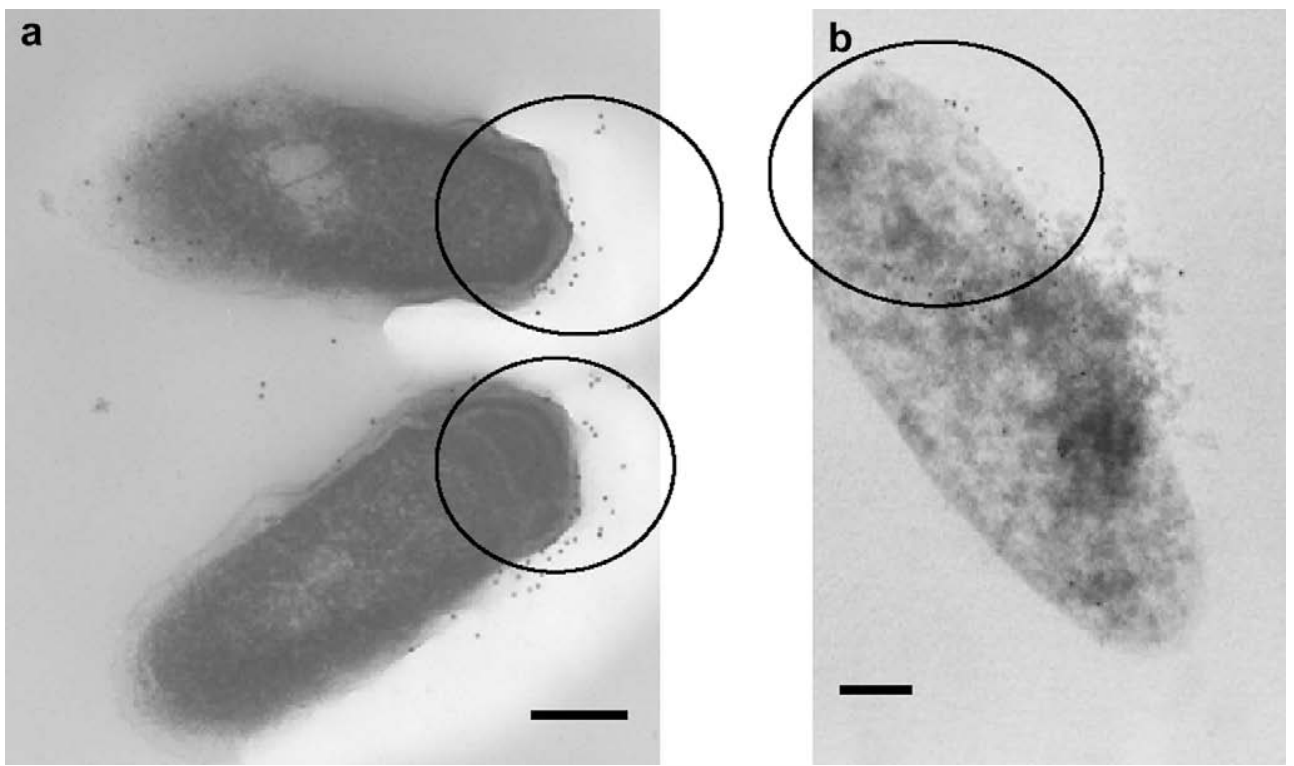

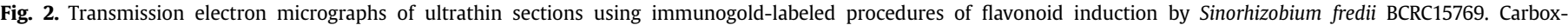

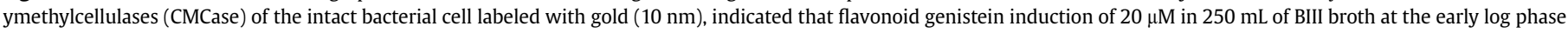
of S. fredii BCRC15769 caused the aggregation of CMCase towards 2 sites of the cell, as shown in the circles of (a) and (b). Bar = $200 \mathrm{~nm}$. 
polymorphisms, and the structure of the nod factor to examine the bean rhizobial community other than the predominant species Rhizobium etli present in soils occupied by the host in northwestern Argentina. Our analysis showed a low similarity between the fastgrowing and slow-growing rhizobia in terms of CMCase distribution. The fast-growing rhizobia, S. fredii BCRC15769 and ATCC35423, had high similarity with S. meliloti BCRC9930. The result is consistent with former reports (Chen et al., 1988; Young, 1996). The group with the highest percentages of staining (50-100\%; Table 1): S. fredii BCRC15769, ATCC35423, and S. meliloti ATCC9930, had high similarity in terms of distribution analysis by labeling. Group 2 (30-50\%; Table 1): R. leguminosarum bv. viceae ATCC10004, R. leguminosarum bv. trifolii 10328, and M. loti 33669, was the next group compared with S. fredii BCRC15769. Group 3 (10-30\%; Table 1): B. japonicum ATCC10324, BCRC13528, and $R$. rhizogenes ATCC11325, had low similarity compared with $S$. fredii BCRC15769. Based on our data in Table 1, we found that the trend of percentage of colloidal gold particles around the membrane is specific to the phylogenetic relationships of some rhizobia. According to the conformation (by means of specific binding of antibody) of CMCase distribution in different species, we could preliminarily classify different species of rhizobia, suggesting that the specific labeling of immunogold would be a source to identify the phylogeny of rhizobia.

In a previous study, S. fredii USDA 191 was incubated with several flavonoids and its $\beta$-galactosidase activity was measured as an indicator of nod ABC-lacZ expression. $\beta$-galactosidase activity was high in response to addition of genistein, apigenin, chrysin, and naringenin, indicating that these four chemicals can induce effective nodulation (Kosslak et al., 1987). Lin et al. (1999) found that genistein and naringenin also induced 5 extracellular proteins of $S$. fredii USDA257, and they postulated that flavonoids affect some physiological processes. In addition to the function we mentioned above, we demonstrated that the flavonoid extracted from G. max, genistein, caused the aggregation of CMCase towards two sides of the cell in S. fredii BCRC15769.

In conclusion, our works presented rhizobial diversity in CMCase antibody-antigen interactions, shown in the immunoelectron microscope diagram, and we found that the flavonoid, genistein, caused the aggregation of CMCase in rhizobia, which enhanced the penetration of rhizobia into plant root hairs in the early stage of symbiosis.

This work was supported by grant NSC94-2313-B-242-001 from the National Science Council, Taiwan. We are grateful to Dr. ChingPiao Liu for technical assistance with transmission electron microscopy, and Dr. Jia-Yau Doong for statistical assistance.

\section{References}

Aguilar, O.M., Lopez, M.V., Donato, M., Morón, B., Soria-Diaz, M.E., Mateos, C. Gil-Serrano, A., Sousa, C., Megias, M., 2006. Phylogeny and nodulation signal molecule of rhizobial populations able to nodulate common beans-other than the predominant species Rhizobium etli-present in soils from the northwest of Argentina. Soil Biology and Biochemistry 38, 573-586.

An, J.M., Lim, W.J., Hong, S.Y., Shin, E.C., Kim, E.J., Kim, Y.K., Park, S.R., Yun, H.D., 2004. Cloning and characterization of cel8A gene from Rhizobium leguminosarum bv, trifolii 1536. Letters in Applied Microbiology 38, 296-300.

Bhat, M.K., Bhat, S., 1997. Cellulase degrading enzymes and their potential industrial applications. Biotechnology Advances 15, 583-620.

Chen, W.X., Yan, G.H., Li, J.L., 1988. Numerical taxonomic study of fast-growing soybean rhizobia and a proposal that Rhizobium fredii be assigned to Sinorhizobium gen. nov. International Journal of Systematic Microbiology 38, 392-397.

Dazzo, F.B., Hubbell, D., 1982. Control of root hair infection. In: Broughton, W. (Ed.) Nitrogen Fixation. Rhizobium, vol. 2. Clarendon Press, Oxford, UK, ISBN 019854552-5, pp. 274-310.

Hu, C.Y., Hsieh, S.L., Wang, J.J., Chen, Y.C., Lin, L.P., 2006. Immunogold labeling of CMcellulase in Sinorhizobium fredii CCRC15769 by electron microscopy. World Journal of Microbiology and Biotechnology 22, 873-880.

Hu, C.Y., Lin, L.P., 2003. Characterization and purification of hydrolytic enzymes in Sinorhizobium fredii CCRC15769. World Journal of Microbiology and Biotechnology 19, 515-522.

Iannetta, P.P.M., Mcmillan, G.P., Sprent, J.I., 1997. Plant cell wall-degrading enzymes of Rhizobium leguminosarum bv. viciae: their role in avoiding the host-plant defence response. Soil Biology and Biochemistry 29, 1019-1021.

Jimenez-zurdo, J.I., Mateos, P.F., Dazzo, F.B., Martinez-Molina, E., 1996a. Influence of the symbiotic plasmid (pSm) on cellulase production by Rhizobium leguminosarum bv. trifolii ANU483. Soil Biology and Biochemistry $28,131-133$.

Jimenez-zurdo, J.I., Mateos, P.F., Dazzo, F.B., Martinez-Molina, E., 1996b. Cell-bound cellulase and polygalacturonase production by Rhizobium and Bradyrhizobium species. Soil Biology and Biochemistry 28, 917-921.

Kosslak, R.M., Bookland, R., Barkei, J., Paaren, H.E., Appelbaum, E.R., 1987. Induction of Bradyrhizobium japonicum common nod genes by isoflavones isolated from Glycine max. Proceedings of the National Academy of Sciences of the United States of America 84, 7428-7432.

Lin, C.C., Chen, Y.C., Song, S.C., Lin, L.P., 1999. Flavonoids as inducers of extracellular proteins and exopolysaccharides of Sinorhizobium fredii. Biology and Fertility of Soils 30, 83-89.

Mateos, P.F., Jimenez-Zurdo, J.I., Chen, J., Squartini, A., Haack, S.K., MartinezMolina, E., Hubbell, D.H., Dazzo, F.B., 1992. Cell-associated pectinolytic and celluloytic enzymes in Rhizobium leguminosarum biovar trifolii. Applied and Environmental Microbiology 58, 1816-1822.

Mergaert, P., D'Haeze, w., Geelen, D., Prom'e, D., van Montagu, M., Geremia, R. Prom'e, J.C., Holsters, M., 1995. Biosynthesis of Azorhizobium caulinodans nod factors. Journal of Biological Chemistry 270, 29217-29223.

Michaud, P., Belaich, A., Courtois, B., Courtois, J., 2002. Cloning, sequencing and overexpression of a Sinorhizobium meliloti M5N1CS carboxymethyl-cellulase gene. Applied Microbiology and Biotechnology 58, 767-771.

Morales, V., Martinez-Molina, E., Hubbell, D., 1984. Cellulase production by Rhizobium. Plant and Soil 80, 407-415.

Vessey, J.K., Chemining'wa, G.N., 2006. The genetic diversity of Rhizobium leguminosarum bv. viciae in cultivated soils of the eastern Canadian prairie. Soil Biology and Biochemistry 38, 153-163.

Young, J.P.W., 1996. Taxonomy of rhizobia. In: Li, F.D. (Ed.), Diversity and Taxonomy of Rhizobia. China Agricultural Science Press, Beijing. 